\title{
FUNGICIDE TIMING FOR CONTROL OF SUMMER ROTS OF APPLES
}

\author{
K.R. EVERETT ${ }^{1}$, O.E. TIMUDO-TORREVILLA ${ }^{1}$, \\ J.T. TAYLOR ${ }^{2}$ and J. YU ${ }^{2}$ \\ ${ }^{1}$ HortResearch, Private Bag 92169, Mt Albert, Auckland, New Zealand \\ ${ }^{2}$ HortResearch, Private Bag 3123, Hamilton, New Zealand \\ Corresponding author: Keverett@hortresearch.co.nz
}

\begin{abstract}
Control of pre-harvest summer rot in cv. Royal Gala apple in the Waikato district during the 2006/2007 growing season was evaluated. There were six treatments and an unsprayed control. Three treatments investigated the effect of timing by applying tolyfluanid, mancozeb, captan and copper sequentially at 10-14 day intervals in October and early November (spring), November and December (early summer) or January and February (late summer). The fourth treatment was two applications of carbendazim in early October (flowering) and there were two biological control treatments, Bacillus subtilis QST713 and Serratia marcescens HR42, applied at 10-14 day intervals from flowering (October) to harvest (February). Compared with the unsprayed treatment, the most effective control was achieved by fungicide applications during either November/December or January/February. Due to large variation in the data, differences were not statistically significant, but mean lesion diameter at final assessment for these treatments was $29 \%$ and $35 \%$ of controls, respectively. The other treatments did not control rots.
\end{abstract}

Keywords: apple summer rots, Colletotrichum acutatum, Botryosphaeria dothidea, timing, biological control, HR42, Serenade ${ }^{\circledR}$.

\section{INTRODUCTION}

Apple summer rots are characterised by small dark spots, ca 1-2 $\mathrm{mm}$ in diameter, which appear on fruit surfaces in January-February. These lesions can increase in size to cover most of the fruit surface by harvest in late February and March. Affected fruit are unmarketable. Summer rots can be caused by Colletotrichum acutatum, Colletotrichum gloeosporioides (teleomorph Glomerella cingulata) and by Botryosphaeria dothidea (Dingley 1969; Jones \& Aldwinckle 1990; Lardner et al. 1999; Cunnington et al. 2007). In the case of the two Colletotrichum species, lesions can become covered with circular rings of pink to orange spores. Rots caused by these fungi are also characterised by the ' $\mathrm{v}$ ' shaped lesion in cross section under the circular spots. Those caused by $B$. dothidea have cup-shaped lesions in section.

At the beginning of this study summer rots were not being adequately controlled by the routine fungicide spray applications, which may have been due to inappropriate timing of the fungicides in relation to the infection periods of the causative fungi. Anecdotal evidence suggested that spraying carbendazim during flowering was controlling summer rots. This paper reports a study of the timing of fungicide applications on the efficacy of these treatments for control of summer rots of apples. In addition, the effectiveness of carbendazim application during flowering and two biological control agents applied throughout the season were tested for control of these rots. 


\section{Fungicide application}

\section{METHODS}

The fungicides used and their respective application rates are detailed in Table 1. The trial had six treatments and an unsprayed control. The first three treatments tested the effect of timing of fungicide application on rot control by applying the same fungicides, tolyfluanid, mancozeb, captan and copper sequentially at 10-14 day intervals, in three different periods. These fungicides were selected because of known efficacy against summer rots and all are registered for use on apples (Young 2007). The order of application was to comply with withholding periods for export (M.R. Butcher, pers. comm.). The three spray periods were spring (October/early November), early summer (November/December) or late summer (January/February) (Table 2). There were two biological control agent treatments, Bacillus subtilis QST 713 and Serratia marcescens HR42, which were applied at 7-14 day intervals throughout the season on 12, 18, 26 October, 1, 7, 21 November, 5, 20 December, 11, 22 January and 9 and 19 February. The sixth treatment was carbendazim, which was applied twice only, during flowering and early fruit set, on 12 and 18 October. All treatments were compared with an unsprayed control. The trial location was at the Blands Research Orchard in Waikato and cv. Royal Gala apple trees were used. Each spray treatment was applied to six replicate trees using a random block design. Products were applied to run-off using a pressurised hand gun sprayer.

\section{Disease assessment}

Disease was assessed by labelling five randomly selected branches per tree and recording the number of infected fruit and lesion sizes at weekly intervals from 11 January-1 March 2007, giving eight assessments. If there were several lesions on a fruit, then the lesion diameter was summed to give a total surface area affected by summer rots.

\section{Isolations}

Isolations were made from a randomly selected sub-sample of 10 fruit (1-2 lesions per fruit) showing symptoms of summer rots from the Blands Research Orchard to identify the fungal pathogens. The surface of each diseased apple fruit was wiped with $70 \%$ ethanol, the skin cut and peeled back, and a portion of the exposed rotted tissue excised and placed on Difco ${ }^{\circledR}$ potato dextrose agar. After 3-6 weeks under UV/daylight fluorescent lights on a 12:12 h light:dark cycle, any resultant fungi were identified by culture and spore morphology. In addition, isolations were also made from eight fruit showing symptoms of summer rots in an adjacent commercial orchard from which C. acutatum had been isolated for the previous two seasons (K.R. Everett, unpubl. data), and eight from the packhouse both orchards used, to determine if the climatic conditions that year had affected the causal organism of summer rots in the Waikato district.

TABLE 1: Products used and rates of active ingredients applied to six trees per treatment of cv. Royal Gala apple trees in a field trial.

\begin{tabular}{llc}
\hline Product & Active ingredient (a.i.) & Rate (a.i./100 litres) \\
\hline Euparen $^{\circledR}$ Multi & tolyfluanid & $50 \mathrm{~g}$ \\
Manzate $^{\circledR}$ 200DF & mancozeb & $150 \mathrm{~g}$ \\
Captan 80W & captan & $100 \mathrm{~g}$ \\
Kocide 2000 $^{\circledR}$ & copper hydroxide & $66.5 \mathrm{~g}$ \\
Goldazim $^{\circledR} 500 \mathrm{SC}$ & carbendazim & $12.5 \mathrm{~g}$ \\
Serenade $^{\circledR}$ & Bacillus subtilis QST 713 & $5 \times 10^{8} \mathrm{cfu} / \mathrm{ml}$ \\
HR42 $^{1}$ & Serratia marcescens HR42 & $1 \times 10^{8} \mathrm{cfu} / \mathrm{ml}$ \\
\hline
\end{tabular}

${ }^{1}$ Experimental HortResearch product. 
TABLE 2: Timing of fungicides applied to cv. Royal Gala apple trees in Blands Research Orchard, Waikato (2006/2007). For each time period the four fungicides were applied sequentially.

\begin{tabular}{lccc}
\hline & \multicolumn{3}{c}{ Timing of application } \\
\cline { 2 - 4 } Date & Spring & Early summer & Late summer \\
\hline 12 Oct & tolyfluanid & & \\
18 Oct & mancozeb & & \\
26 Oct & captan & & \\
1 Nov & copper hydroxide & & \\
7 Nov & & tolyfluanid & \\
$21 \mathrm{Nov}$ & mancozeb & tolyfluanid \\
$5 \mathrm{Dec}$ & captan & mancozeb \\
$20 \mathrm{Dec}$ & & & copper hydroxide \\
$11 \mathrm{Jan}$ & & & copper hydroxide \\
$22 \mathrm{Jan}$ & & & \\
$9 \mathrm{Feb}$ & & & \\
$19 \mathrm{Feb}$ & & & \\
\hline
\end{tabular}

\section{Statistical analysis}

$\mathrm{SAS}^{\circledR}$ (version 8.2) and Excel $^{\circledR}$ were used for data analysis. Tree is the experimental unit. Tree means at each week were calculated by averaging the lesion diameter measurements over all the fruit. Treatment means and their standard errors were calculated using the tree means weighted by number of fruit per tree. Each individual tree mean was calculated from the mean of the fruit on the five assessed branches, and treatment tree means from the mean of the six replicate trees. There were unequal numbers of fruit per branch. Dropouts were handled by Last Observation Carry Forward (LOCF), which is a method for imputation of missing values (Powers et al. 2007). The last remaining observation is carried through to remaining time points. It is assumed that dropout is due to fruit missing at random. Statistical differences were calculated by generating $\mathrm{P}$ values using a one-tailed paired t test of the final point response.

\section{RESULTS}

Treatment means and their standard errors are plotted in Figure 1. Results of t tests provided weak evidence that fungicide applications in early and late summer reduced lesion size compared to untreated controls $(\mathrm{P}=0.16$ and 0.18 respectively). Mean lesion diameter of these two treatments $(0.5$ and $0.6 \mathrm{~mm})$ was $29 \%$ and $35 \%$ respectively of untreated controls $(1.7 \mathrm{~mm})$. These differences were not statistically significant due to large variability between trees. The other treatment $P$ values were $\geq 0.39$ and were not significant.

The differences between treatments of fruit that dropped from the trees during the treatments were small (Fig. 2) and fruit retention was not consistently related to disease control confirming the assumption that dropout is due to fruit missing at random.

Botryosphaeria dothidea was isolated from all 12 of the small dark lesions on the 10 fruit from the Blands Research Orchard. Colletotrichum acutatum was isolated from all similar lesions from 12 fruit from an adjacent commercial orchard, and from rejected fruit at its packhouse. 


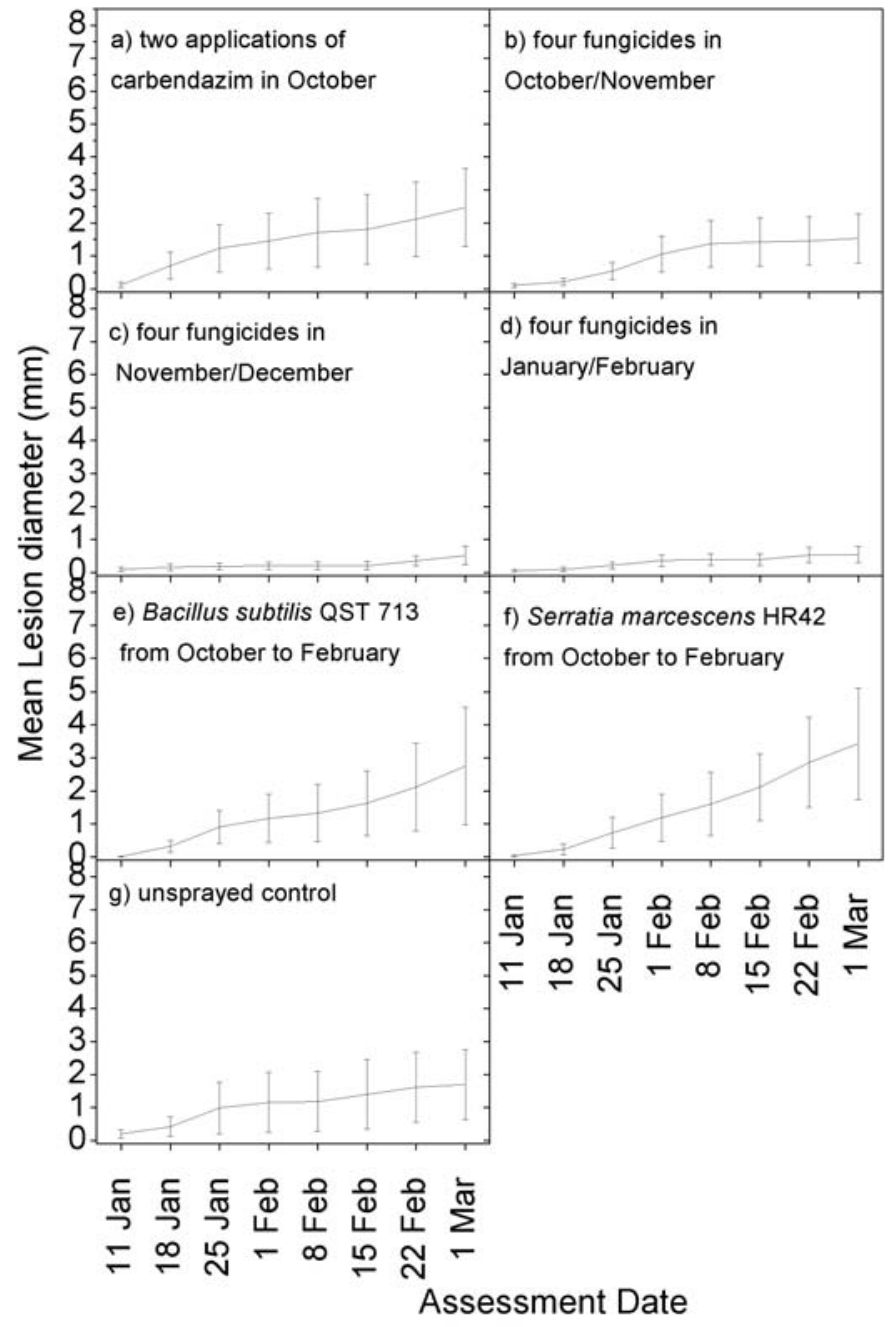

FIGURE 1: Mean diameters per fruit $(\mathrm{mm})$ of lesions caused by Botryosphaeria dothidea at eight weekly assessments. Bars are standard errors of the means. (a) two applications of carbendazim in October, (b) four fungicides in October/November, (c) four fungicides in November/ December, (d) four fungicides in January/February, (e) Bacillus subtilis QST 713 from October to February, (f) Serratia marcescens HR42 from October to February and (g) unsprayed control. 


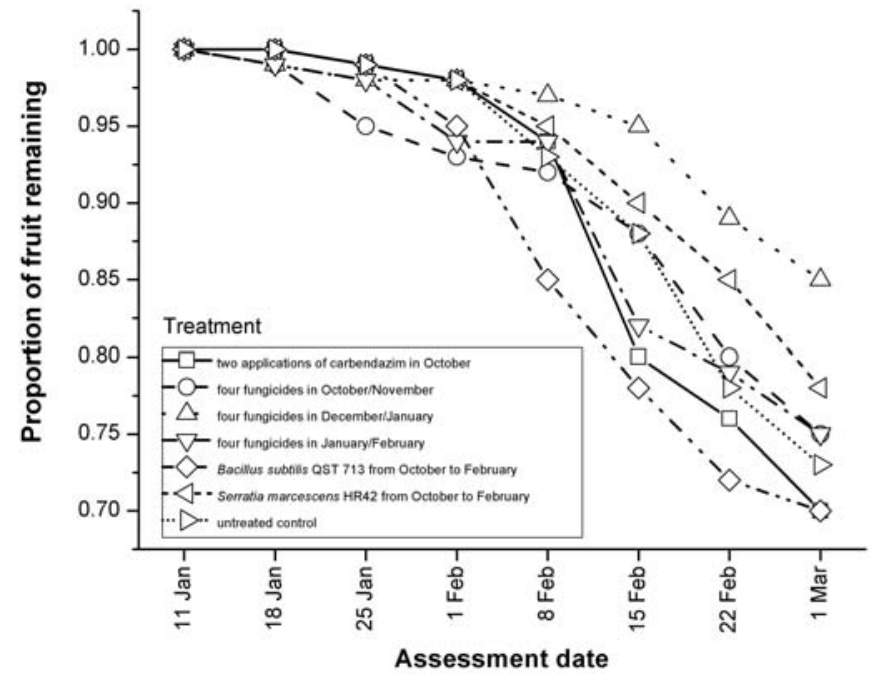

FIGURE 2: The relative proportion of fruit remaining on trees during the summer, for each of the seven treatments. (a) two applications of carbendazim in October, (b) four fungicides in October/November, (c) four fungicides in November/December, (d) four fungicides in January/February, (e) Bacillus subtilis QST 713 from October to February, (f) Serratia marcescens HR42 from October to February and (g) unsprayed control.

\section{DISCUSSION}

Best control of summer rot disease of apples was achieved by applying one application each of tolyfluanid, mancozeb, captan and copper sequentially at 10-14 day intervals during either early or late summer (November/December or January/February). However, this result was not statistically significant due to high variability between trees. A larger sample size is recommended to reduce variability for future trials. In studies on timing of application of ergosterol biosynthesis-inhibiting fungicides, Kim \& Uhm (2002) found that applications were most effective in mid to late summer for control of summer rots of apples caused by $B$. dothidea in Korea. Although different fungicides were used, the most effective control was obtained when fungicide applications were applied at an equivalent time in the season to the time best control was achieved in the present study.

In New Zealand, $B$. dothidea is occasionally isolated from summer rots, but its incidence is low. For instance, in $199946 \%$ of isolations from fruit rots from 13 orchards in the Waikato district by ENZA yielded C. acutatum, and B. dothidea was not found. In the same survey G. cingulata was not isolated (M.R. Butcher, pers. comm.). In contrast, the summer rots on the Blands Research Orchard were caused by B. dothidea. Because lesions from fruit from adjacent orchards yielded $C$. acutatum seasonal weather patterns are not likely to be the reason for this difference.

The Blands Research Orchard was selected on the basis of its likelihood to have high disease pressure because it was not managed using standard commercial practices. Thus, it is an unusual orchard, and not typical of other orchards in the Waikato. These results suggest that regular spray programmes on commercial orchards control rots caused by $B$. dothidea . 
Over 30 years ago, control of summer rots caused by Glomerella cingulata was achieved by applying captafol sprays four times at 13-15 day intervals in spring (September/October) and in early summer (November/December) (Brook 1977). However, captafol is no longer available, and more recent studies have shown that the disease is now most commonly caused by C. acutatum (M.A. Manning, pers. comm.). The present results suggest that 30 years later summer rots are better controlled by fungicide applications in early and late summer. However, this needs confirmation by testing on an orchard with a high incidence of summer rots caused by C. acutatum.

\section{ACKNOWLEDGEMENTS}

This study was supported by a grant from the MAF Sustainable Farming Fund, the Waikato Fruitgrowers' Association, Nelson Group 8 and Pipfruit NZ Ltd. Thanks to Nihal de Silva for the statistical analysis.

\section{REFERENCES}

Brook PJ 1977. Glomerella cingulata and bitter rot of apple. New Zealand Journal of Agricultural Research 20(4): 547-555.

Cunnington JH, Priest MJ, Powney RA, Cother NJ 2007. Diversity of Botryosphaeria species on horticultural plants in Victoria and New South Wales. Australasian Plant Pathology 36: 157-159.

Dingley JM 1969. Records of Plant Diseases in New Zealand. A.R. Shearer, Government Printer, Wellington, New Zealand.

Jones AL, Aldwinckle HS 1990. Compendium of Apple and Pear Diseases. APS Press, St. Paul, Minnesota, USA.

Kim D, Uhm J 2002. Effect of application timing of ergosterol biosynthesis-inhibiting fungicides on the suppression of disease and latent infection of apple white rot caused by Botryosphaeria dothidea. Journal of General Plant Pathology 68(3): 237-245.

Lardner R, Johnston PR, Plummer KM, Pearson MN 1999. Morphological and molecular analysis of Colletotrichum acutatum sensu lato. Mycological Research 103(3): 275-285.

Powers PS, Bannon Y, Eubanks R, McCormick T 2007. Quetiapine in anorexia nervosa patients: an open label outpatient pilot study. International Journal of Eating Disorders 40 (1): 21-26

Young S ed. 2007. New Zealand Agrichemical Manual. Agri Media Ltd., Ashcroft House, Tancreds Road, Christchurch. 